\title{
Endodontic Treatment of Lower Anterior Teeth with Multiple Canals
}

\author{
Mirjana Vujašković1, Nikola Stojanović2 , Goran Vujašković3 \\ ${ }^{1}$ Department for Restorative Dentistry and Endodontics, School of Dentistry, University of Belgrade, Belgrade, Serbia; \\ ${ }^{2}$ Department for Restorative Dentistry and Endodontics, School of Medicine, University of East Sarajevo, Foča, \\ Bosnia and Herzegovina; \\ 3Institute of Anatomy, School of Dentistry, University of Belgrade, Belgrade, Serbia
}

\begin{abstract}
SUMMARY
Introduction Knowledge of root canal morphology is one of the main prerequisites for successful endodontic treatment. We present the case of a patient with multiple canals in lower anterior teeth which were treated endodontically. Case Report To a 45-year-old patient endodontic treatment was applied on lower left lateral incisor, lower right central and lateral incisor and lower right canine. These teeth were previously prepared for prosthetic crowns. All involved teeth had two canals which were not visible on the primary radiographs. Gracility of remaining tooth structure and canals and the presence of two canals in each tooth required additional radiographs for verification of multiple canals. Careful biomechanical instrumentation and irrigation with use of lubrication due to narrow canals was performed. The canals were obturated with gutta-percha using lateral compaction technique and Acroseal (Septodont) paste. On the control checkup after eight months, the patient was asymptomatic, while clinical finding was normal.

Conclusion Complexity of presented case was even more significant because these teeth were prepared to support prosthetic superstructure and crowns, and every "forgotten" canal is an iatrogenic error.
\end{abstract}

Keywords: endodontic treatment; mandibular canine and incisors; canal branching

\section{INTRODUCTION}

The failure of endodontic treatment may be the result of "forgotten", non-detected canals, inadequate biomechanical instrumentation and irrigation or incomplete obturation. Variations in the number of roots and canals (position, direction and morphology), and the presence of lateral or accessory canals and branches are often described in the literature [1]. In addition to good knowledge of canal morphology, it is necessary to realize the treatment complexity, particularly if prosthetic reconstruction is required after endodontic treatment completion.

Numerous researchers have studied morphology of the canal system of lower anterior teeth. Mandibular canine is usually described to have one root and one canal [2]. Vertucci [1], Pineda and Kuttler [3], Green [4] and D'Arcangelo et al. [5], in their studies, have indicated the presence of two canals with one or two separate openings in $15 \%$ of samples. Laurichesse et al. [6] have described the presence of one root and two canals in $2 \%$ of samples and two roots and two canals in $1 \%$ of cases. If two canals are present, they usually join into one opening [7]. D’Arcangelo et al. [5] have reported mandibular canine with two roots and two canals. Holtzman [8] and Orguneser and Kartal [9] have described endodontic treatment of a lower canine with three canals and one root. Heiling et al. [10] have shown an extremely rare case of a mandibular canine with two roots and three canals.

Mandibular incisors have two canals in 11-58\% according to the literature, and they are in most cases joined into one single canal in the apical third at about $1-3 \mathrm{~mm}$ to the apex $[1,11,12]$. Miyashita et al. [13] have recorded two canals with one opening at the apex in $12.4 \%$ of the tested samples, while two canals with two separate openings at the apex have been found in only $3 \%$. Ingle and Bakland [2] have found two canals in $23.4 \%$ of mandibular central and $14.7 \%$ of lateral incisors. A study by Indian authors [11] on 480 extracted mandibular incisors reported one canal present in $63.75 \%$, two canals with one opening in $36.5 \%$ and two canals with two openings in $6.25 \%$ of cases. The presence of two roots and two canals have also been noted [14]. The presence of lateral canals, which were more common in middle third than in apical third, has also been described $[11,12]$.

A great problem is the fact that during endodontic treatment of these teeth, in a small percentage all canals are found and treated $[11,15]$. This results in failure of endodontic treatment, with visible changes radiographically which are often surgically treated, even though the reason for failure is "forgotten" or non-instrumented canal. During access cavity preparation lingual axial angulation of crowns for about 20 degrees, and mesial axial 
angulation for about 17 degrees should be considered. In order to detect lingual canal it is necessary to extend access cavity in inciso-gingival direction.

\section{CASE REPORT}

A 45-year-old woman showed up at the Clinic for restorative Dentistry and endodontics, School of Dentistry in Belgrade for endodontic treatment of the lower anterior teeth, previously prepared for prosthetic crowns. Lower left lateral incisor, lower right central and lateral incisor and lower right canine were proposed for endodontic treatment. Teeth were vital and percussion test was negative. Analysis of preoperative diagnostic radiograph revealed one canal in the lower left lateral incisor (Figure 1), one canal in right central and lateral incisor and two separate canals in lower right canine were clearly visible on the radiograph (Figure 2).

After obtaining dry field and local anaesthesia, access cavity was prepared on the lower left lateral incisor. It was desirable to preserve the coronal part of the tooth as much as possible, without compromising the principles of endodontic treatment. By probing the bottom of the access cavity the entrance of the root canal was located. When a thin instrument \#8-10 was placed in the canal, buccal inclination of the instrument was visible but the instrument could not be moved either in central or lingual direction. There was assumption about the existence of the lingual canal even though it was not visible on the

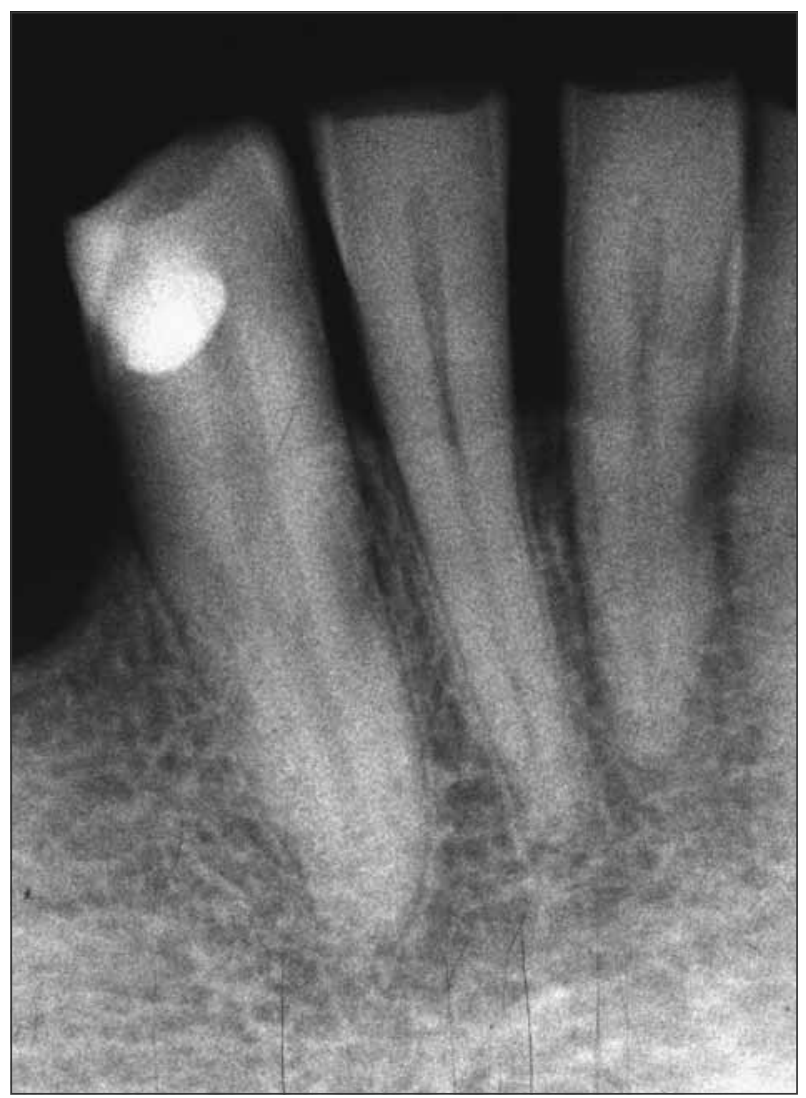

Figure 1. One canal in the tooth 32 as shown on preoperative radiograph

Slika 1. Na radiogramu se vidi jedan kanal donjeg levog lateralnog sekutića radiograph. By careful exploration, lingual entrance was detected, two instruments were placed in the canals and another radiograph was taken (Figure 3 ). The entrance of the canal was instrumented by Gates Glidden bur \#2. Working length was determined using apex locator Root ZX (Morita, Europe GmbH, Frakfurt, Germany). The canals were instrumented using flexible hand canal instruments and Canal+ (Septodont) as lubricant. Step back technique and irrigation with $0.5 \% \mathrm{NaOCl}$ solution were applied for canal instrumentation. The canals were obturated using Acroseal (Septodont) paste and gutta-percha and additional radiograph was taken (Figure 4).

Three lower right anterior teeth were endodontically treated in the next appointment. Preoperative diagnostic images of the lower right central and lateral incisor showed that both of them had one canal, while in the right canine two separate canals were visible (Figure 2). Having experience with multiple canals in the lower left lateral incisor and visible two canals in the lower right canine, there was an assumption that all three teeth may have two canals. Endodontic treatment was conducted as described for the lower left lateral incisor. By inserting thin instruments in the canals, two canals were validated in the three lower right anterior teeth (Figure 5). Canals were instrumented, irrigated and obturated with guttapercha using lateral compaction technique and Acroseal paste. Radiography was performed from two different angles to be able to register two canals (Figures 6 and 7). Control checkup after eight months was performed and patient had no subjective problems.

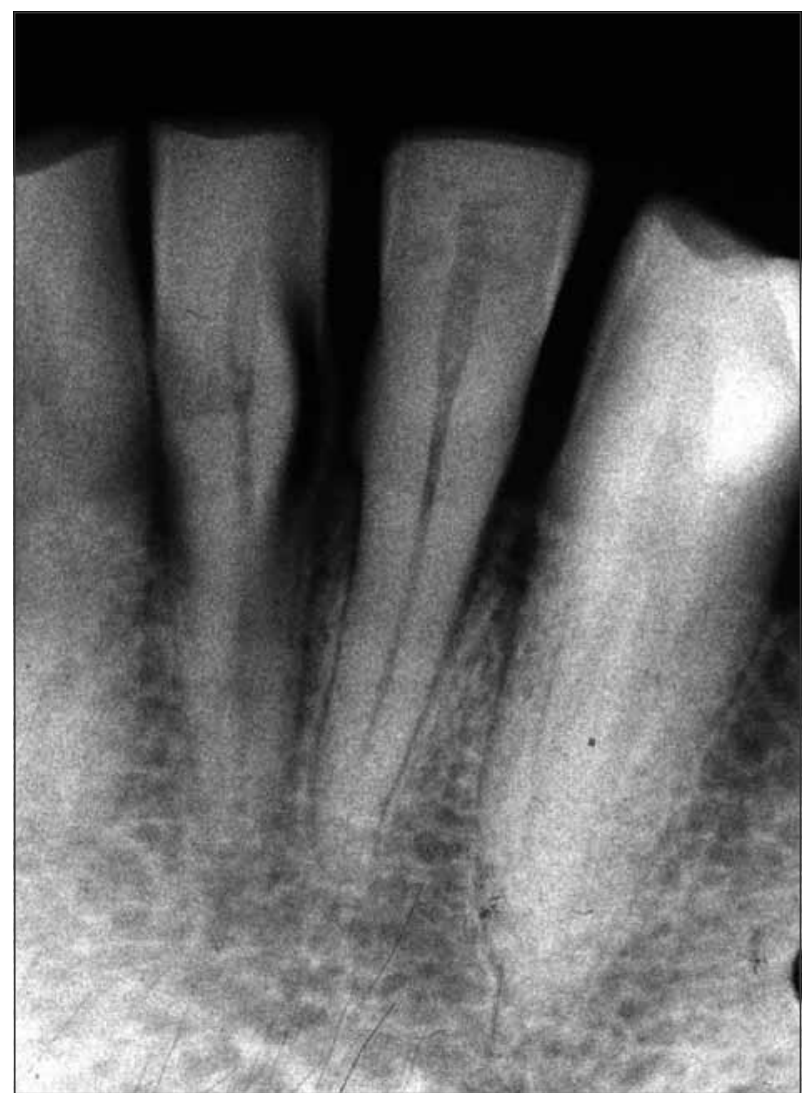

Figure 2. One root canal in the teeth 41,42 and two root canals in the tooth 43 (preoperative radiograph)

Slika 2. Na preoperacionom radiogramu se vide po jedan kanal zuba 41 i 42 i dva kanala zuba 43 


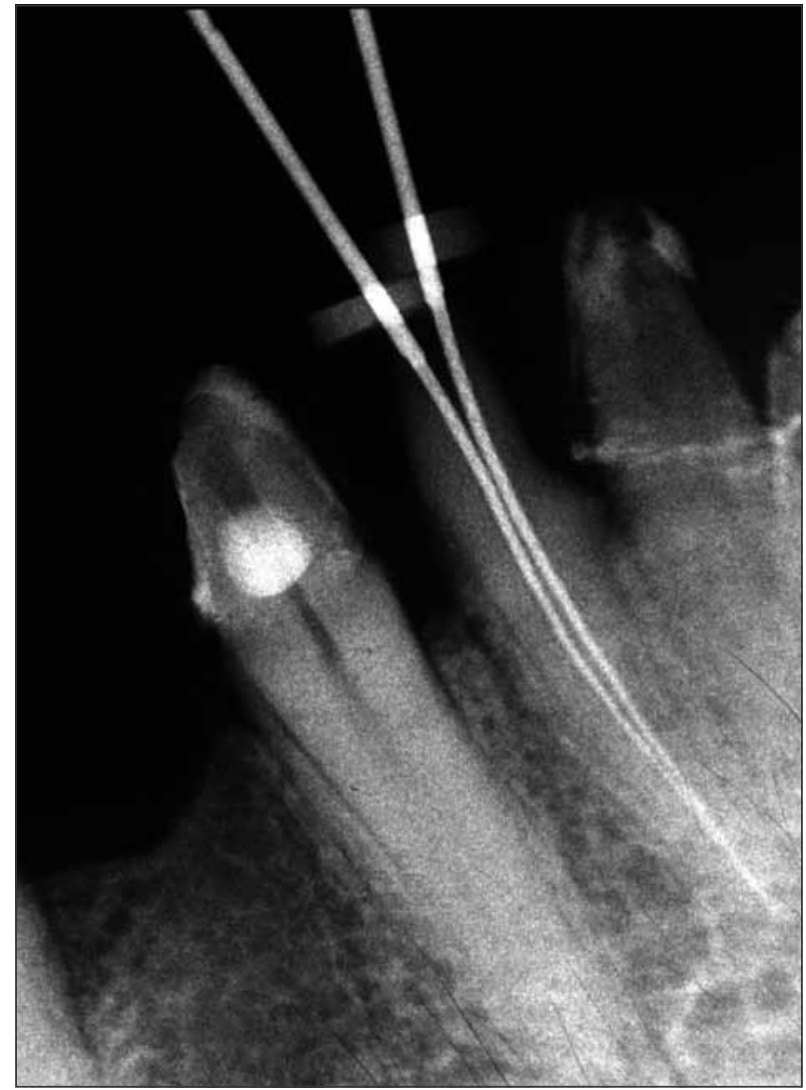

Figure 3. Endodontic files placed in two canals

Slika 3. Postavljanje kanalnih instrumenata u dva kanala radi dijagnostike

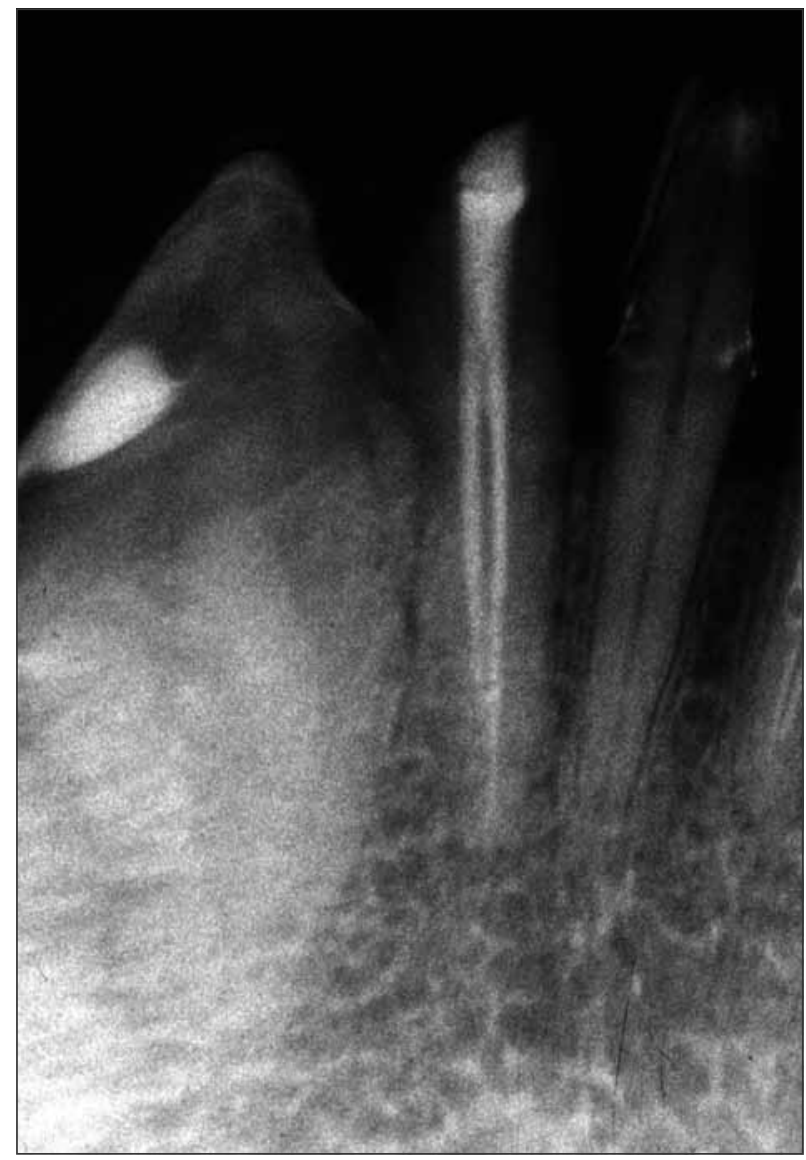

Figure 4. Final obturation of two root canals Slika 4. Konačno punjenje oba kanala korena

\section{DISCUSSION}

Detecting two canals in clinical situations can be complicated because of the superposition of canals on the radiograph. Careful analysis can reveal direction of a root canal where sometimes sudden disappearance of the canal may indicate a possible doubling the canal $[16,17]$. In this case, at the same time, advantage and disadvantage was that the teeth were prepared for prosthetic crowns. It was difficult to prepare adequate access cavity because of preservation of the crown on one hand and not compromising endodontic treatment on the other hand. Instrument position during the initial exploration of the canal clearly indicated first slope of the canal to the buccal and second slope to the lingual. As few teeth were already shown to have two canals, including the canine, to verify the canal and obtain working length, several radiographs were taken from different angles. On some radiographs, it seemed as superposition, but on some the presence of two separate canals was obvious. The presence of two canals in mandibular incisors is quite often $[1,2,3]$ as shown in in vitro studies on extracted teeth, whereas in clinical practice one of the canals is often forgotten leading to the failure of endodontic therapy.

Two canals are more common for lower incisors than lower canine. It should be pointed out that the complexity of canal system in one tooth usually requires better analysis of remaining teeth and their root canals.

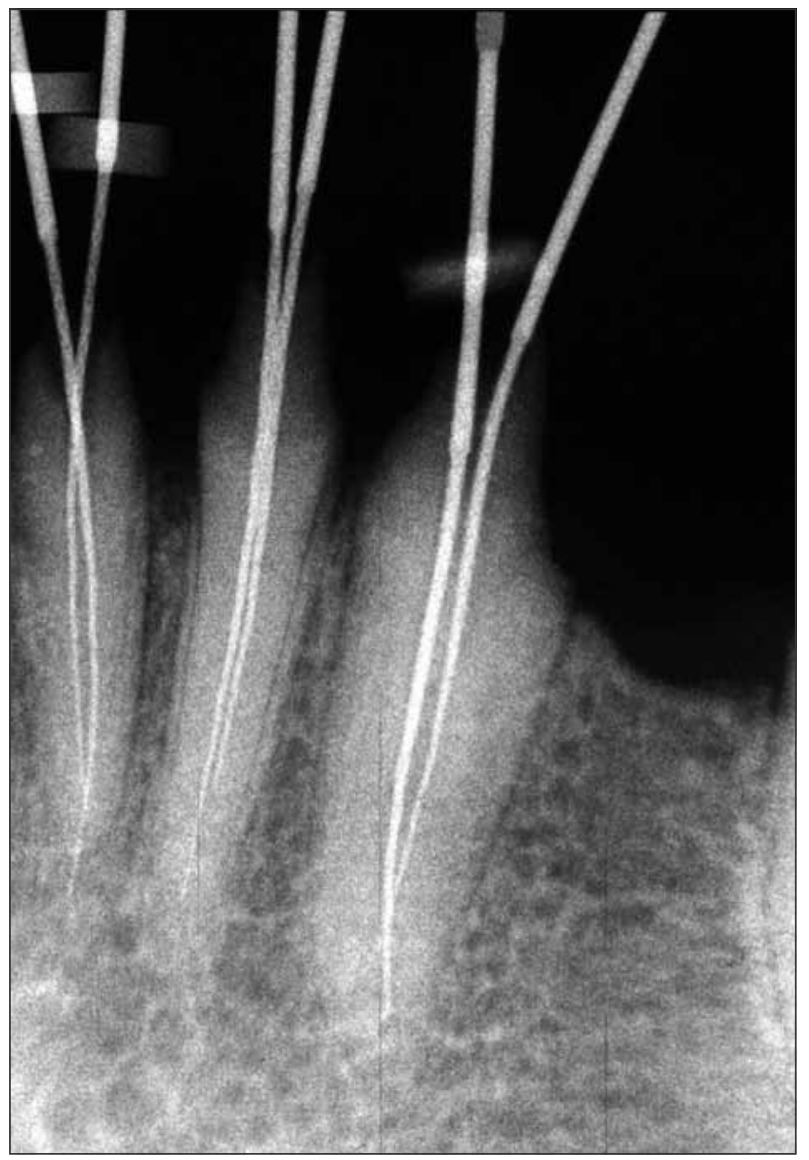

Figure 5. Endodontic files placed in two canals of the teeth 41,42 and 43 Slika 5. Postavljanje kanalnih instrumenata u dva kanala zuba 41, 42 i 43 radi dijagnostike 


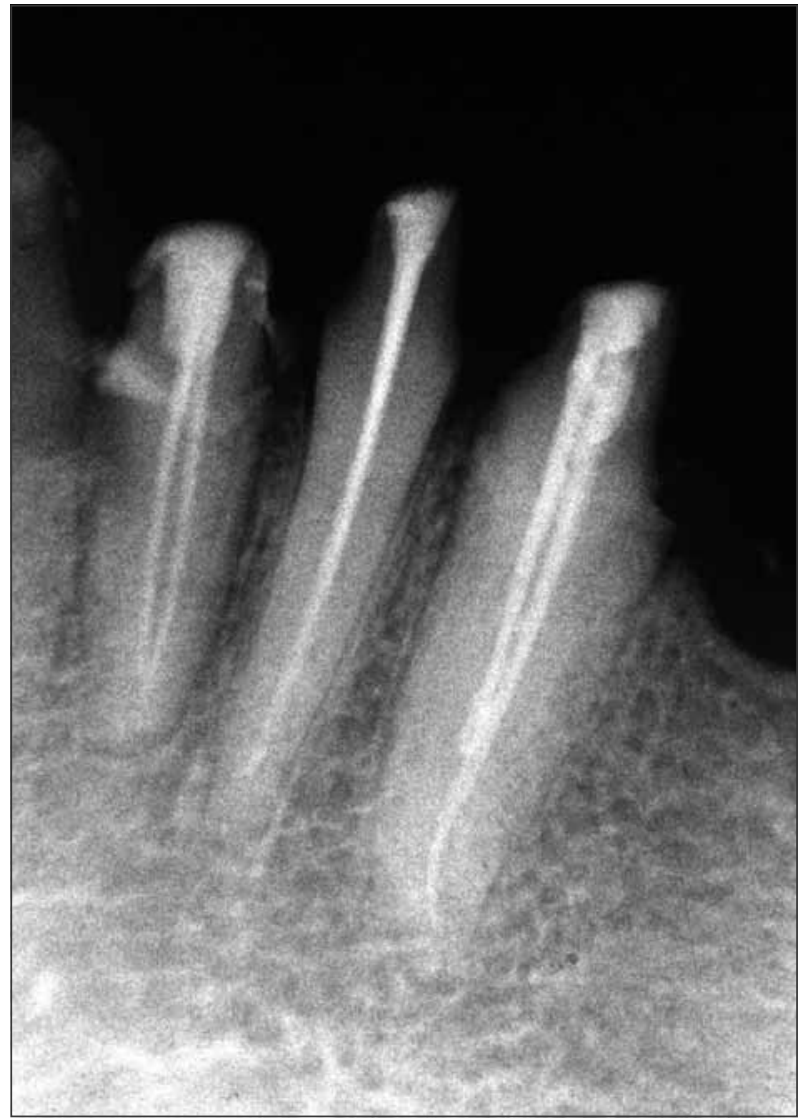

Figure 6. Final obturation of two canals in the lower right central and lateral incisors

Slika 6. Konačno punjenje oba kanala korena donjeg desnog centralnog i lateralnog sekutića

\section{REFERENCES}

1. Vertucci FJ. Root canal anatomy of the human permanent teeth. Oral Surg Oral Med Oral Pathol. 1984; 58:589-99.

2. Ingle IJ, Bakland LK. Endodontics. 4th ed. Philadelphia: Lea \& Febiger; 1994

3. Pineda F, Kuttler Y. Mesiodistal and buccolingual roentgenographic investigation of 7,275 root canals. Oral Surg Oral Med Oral Patol. 1972; 33:101-10.

4. Green D. Double canal in single roots. Oral Surg Oral Med Oral Pathol. 1973; 35:689-96.

5. D'Arcangelo C, Varvara G, De Fazio P. Root canal treatment in mandibular canines with two roots: a report of two cases. Int Endod I. 2001; 34:331-4

6. Laurichesse JM, Maestroni J, Breillat J. Endodontie Clininique. 1st ed. Paris, France: Ed CdP; 1986

7. Calişkan MK, Pehlivan Y, Sepetçioğlu F, Türkün M, Tuncer SS. Root canal morphology of human permanent teeth in a Turkish population. J Endod. 1995; 21:200-4.

8. Holtzman L. Root canal treatment of a mandibular canine with three root canals. Case report. Int Endod I. 1997; 30:291-3.

9. Orguneser A, Kartal N. Three canals and two foramina in a mandibular canine. J Endod. 1998; 24:444-5.

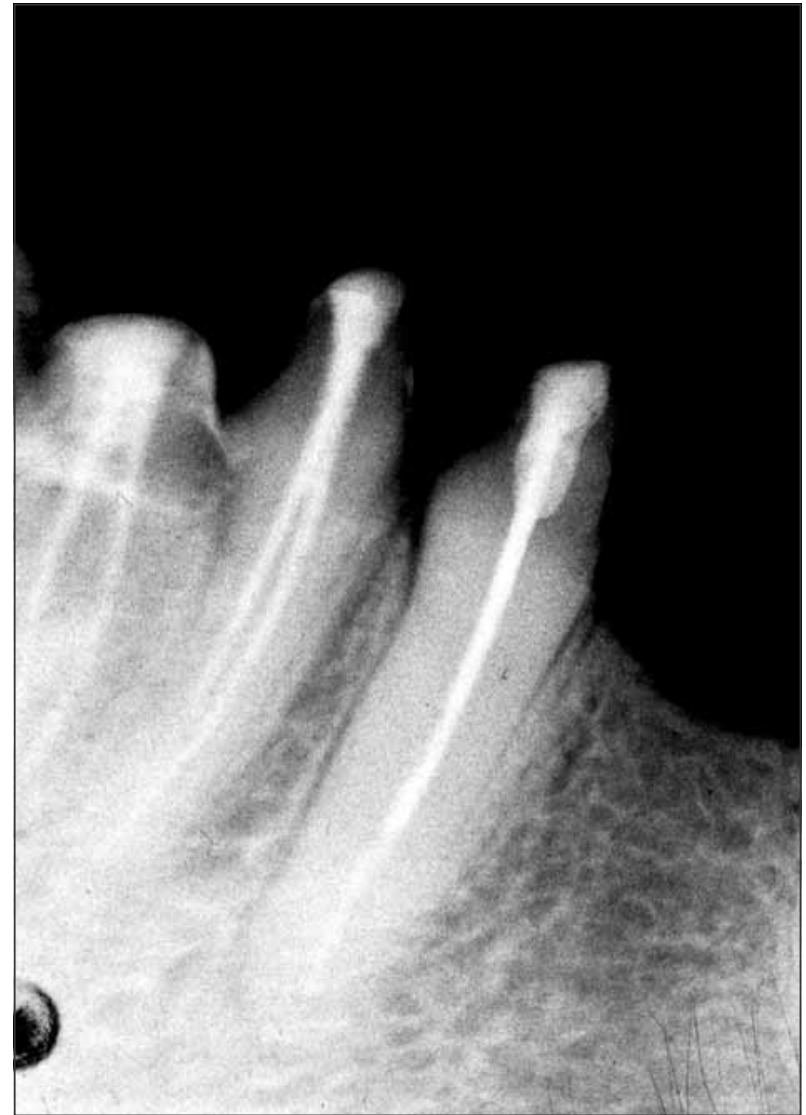

Figure 7. Final obturation of the lower right canine Slika 7. Konačno punjenje donjeg desnog očnjaka

10. Heiling I, Gotlieb-Dadon I, Chandler NP. Mandibular canine with two roots and three root canals. Endod Dent Traumatol. 1995; 11:301-2.

11. Boruah LC, Pertin O, Bhuyan AC, Kalita C. Root canal morphology of permanent mandibular incisors in northeast Indian population - in vitro study using a root canal staining technique. ENDO. 2010; 4:273-7.

12. Sert S, Aslanalp $\vee$, Tanalp J. Investigation of the root canal configurations of mandibular permanent teeth in the Turkish population. Int Endod ). 1985; 35:494-9.

13. Miyashita M, Kasahara E, Yasuda E, Yamamoto A. Root canal system of the mandibular incisor. J Endod. 1997; 23:479-84.

14. Funato A, Funato H, Matsumoto K. Mandibular central incisor with two canals. Endod Dent Traumatol. 1998; 14:285-6.

15. Neo J, Chee LF. A retrospective clinical study of endodontic treated mandibular incisors in selected Chinese population. Oral Surg Oral Med Oral Pathol. 1990; 70:782-3.

16. Vujašković M. Odontometrija u endodonciji. Beograd: autorsko izdanje; 2005.

17. Vujašković $M$, Karadžić B, Miletić V. Endodontsko lečenje drugog donjeg premolara zuba sa taurodontizmom. Srp Arh Celok Lek. 2008; 136(5-6):280-4. 


\title{
Endodontsko lečenje donjih frontalnih zuba sa višekanalnim sistemom
}

\author{
Mirjana Vujašković1, Nikola Stojanović2, Goran Vujašković3 \\ ${ }^{1}$ Klinika za bolesti zuba i endodonciju, Stomatološki fakultet, Univerzitet u Beogradu, Beograd, Srbija; \\ ${ }^{2}$ Katedra za bolesti zuba i endodonciju, Medicinski fakultet, Univerzitet u Istočnom Sarajevu, Foča, Bosna i Hercegovina; \\ 3Institut za anatomiju, Stomatološki fakultet, Univerzitet u Beogradu, Beograd, Srbija
}

\begin{abstract}
KRATAK SADRŽAJ
Uvod Poznavanje morfoloških osobina kanala korena zuba jedan je od osnovnih preduslova uspešne endodontske terapije. Prikazujemo slučaj pacijenta sa višekanalnim sistemima donjih frontalnih zuba koje je bilo neophodno endodontski lečiti. Prikaz slučaja Kod žene stare 45 godina urađena je endodontska terapija na donjem levom lateralnom sekutiću, donjem desnom centralnom i lateralnom sekutiću i donjem desnom očnjaku. Zubi su prethodno bili pripremljeni za protetičke krunice. Svi uključeni zubi su imali po dva kanala koja nisu bila vidljiva na primarnom radiogramu. Gracilnost preostale krunice zuba, gracilnost kanala i zastupljenost po dva kanala u svakom zubu zahtevali su dodatna snimanja radi potvrde udvojenosti. Bila je neophodna pažljiva biomehanička obrada uz primenu lubrikanta i irigansa zbog otežane prohodnosti kanala. Kanali su napunjeni lateralnom kompaktažom gutaperke uz primenu paste Acroseal (Septodont). Na kontrolnom pregledu osam meseci kasnije pacijentkinja nije imala subjektivnih tegoba, a klinički nalaz je bio normalan.

Zaključak Sagledavanje kompleksnosti ovakvog slučaja radi endodontskog lečenja je značajno, jer su ovi zubi bili dalje opterećeni protetičkim nadogradnjama i krunicama, pa bi svaki „zaboravljeni” kanal bio lekarska greška u okviru preprotetičke pripreme.
\end{abstract}

Ključne reči: endodontsko lečenje; mandibularni očnjak i sekutići; udvojenost kanala

\section{UVOD}

Neuspeh endodontskog lečenja može biti rezultat tzv. zaboravljenih (neotkrivenih) kanala korena zuba, nedovoljnog čišćenja i obrade i nepotpune opturacije kanala korena. Opisane su brojne varijacije broja korenova i kanala zuba (položaj, pravac pružanja, morfološki izgled), broja lateralnih i transverzalnih kanalića i anastomoza [1]. Osim dobrog poznavanja morfoloških osobina, neophodno je upoznati se i sa složenošću kanalnog sistema, posebno ukoliko je potrebna endodontska terapija i potom protetička rekonstrukcija zuba.

Mnoge studije su opisale morfološke odlike kanalnog sistema donjih frontalnih zuba. Mandibularni očnjak obično ima jedan koren i jedan kanal [2]. Vertuči (Vertucci) [1], Pineda (Pineda) i Katler (Kuttler) [3], Grin (Green) [4] i D'Arkanđelo (D'Arcangelo) i saradnici [5] u svojim studijama ustanovili su dva kanala s jednim ili dva odvojena otvora u 15\% ispitivanih uzoraka zuba. Lorišesova (Laurichesse) i saradnici [6] opisali su u 2\% ispitivanih uzoraka dva kanala u jednom korenu, a u 1\% uzoraka dva korena i dva kanala. Ako postoje dva kanala, ona se obično spajaju u jedan s jednim otvorom na vrhu korena [7]. D’Arkanđelo i saradnici [5] navode primer dvokorenog mandibularnog očnjaka sa dva kanala. Holcman (Holtzman) [8] i Orguneser (Orguneser) i Kartal (Kartal) [9] prikazali su slučaj endodontskog lečenja donjeg očnjaka sa tri kanala u jednom korenu. Hajling (Heiling) i saradnici [10] opisali su izuzetno redak slučaj dvokorenog mandibularnog očnjaka sa tri kanala.

U literaturi se navodi da 11-58\% mandibularnih sekutića ima dva kanala i da se u većini slučajeva spajaju u jedan kanal u apeksnoj trećini, na 1-3 mm od apeksa $[1,11,12]$. Mijašita (Miyashita) i saradnici [13] su u 12,4\% ispitivanog uzorka ustanovili dva kanala koja imaju jedan otvor u vrhu korena, a u svega $3 \%$ uzoraka dva kanala koja se otvaraju sa dva odvojena otvora u vrhu korena. Ingl (Ingle) i Baklend (Bakland) [2] su utvrdili dva kanala u 23,4\% uzoraka kod centralnog i u 14,7\% slučajeva kod lateralnog mandibularnog sekutića. Studija indijskih autora [11] na 480 ekstrahovanih mandibularnih sekutića ukazala je na jedan kanal u 63,75\% ispitivanih uzoraka, dva kanala $\mathrm{s}$ jednim otvorom u $36,5 \%$ uzoraka i dva kanala sa dva otvora u $6,25 \%$ slučajeva. Zabeleženo je i postojanje dva korena sa dva kanala [14]. Ustanovljeni su i lateralni kanali, koji su češći u srednjoj trećini, a nešto se ređe javljaju u apeksnoj trećini $[11,12]$.

Veliki problem predstavlja činjenica da se tokom endodontske terapije na ovim zubima u retkim prilikama pronalaze i endodontski leče dva kanala $[11,15]$. To dovodi do brojnih neuspeha endodontske terapije, koji su praćeni radiografski vidljivim promenama na periapeksu zuba i često se hirurški rešavaju, iako u osnovi stoji tzv. zaboravljeni neobrađeni kanal. Prilikom formiranja pristupnog kaviteta treba imati u vidu lingvoaksijalnu angulaciju krunice od 20 stepeni, kao i mezioaksijalnu angulaciju krunice zuba od 17 stepeni. Da bi se otkrio lingvalni kanal, neophodna je ekstenzija kaviteta u incizogingivalnom smeru.

\section{PRIKAZ SLUČAJA}

Žena stara 45 godina javila se na Kliniku za bolesti zuba Stomatološkog fakulteta u Beogradu radi endodontskog lečenja donjih frontalnih zuba koji su prethodno bili ispreparisani za protetičke krunice. Trebalo je endodontski zbrinuti donji levi lateralni sekutić, donji desni centralni i lateralni sekutić i donji desni očnjak. Vitalitet zuba je bio očuvan i nije bilo perkutorne osetljivosti. Analizom preoperacionog dijagnostičkog radiografskog snimka u okviru preprotetičke pripreme na donjem levom lateralnom sekutiću uočen je jasno vidljiv jedan kanal (Slika 1). 
Na snimku donje desne strane ustanovljeni su jedan kanal centralnog i lateralnog sekutića i dva razdvojena kanala donjeg očnjaka (Slika 2).

Nakon pripreme polja rada i primene anestezije pristupilo se formiranju pristupnog kaviteta na donjem levom lateralnom sekutiću. Bilo je poželjno očuvati krunični deo zuba koliko je to moguće, da se ne ugroze principi endodontskog lečenja. Sondiranjem dna pristupnog kaviteta, gracilnih ispreparisanih krunica zuba, pozicionirao se ulaz u kanal. Tokom postavljanja tankog kanalnog instrumenta \#8-10 bile su vidljive inklinacija instrumenta ka bukalnoj površini i gracilnost kanala, pri čemu instrument nije mogao da se pomera centralno i lingvalno. Pretpostavka je bila da postoji i lingvalni kanal, iako se na snimku on nije video. Pažljivim ispitivanjem uočen je ulaz u lingvalni kanal, ubačena su dva kanalna instrumenta, što je registrovano radiogramom (Slika 3). Ulaz u kanal je obrađen Gejts-Glidenovim (Gates-Gliden) borerom \#2. Radna dužina je određena primenom apeks lokatora Root ZX (Morita, Europe GmbH, Frankfurt, Nemačka). Potom su za obradu kanala korišćeni fleksibilni kanalni instrumenti uz primenu lubrikanta Canal+ (Septodont). Primenom tzv. step back tehnike, biomehanička obrada je upotpunjena irigacijom rastvorom $\mathrm{NaOCl}$ od $0,5 \%$. Kanali su potom napunjeni pastom Acroseal (Septodont), nakon čega je načinjen radiogram konačnog kanalnog punjenja (Slika 4).

U sledećoj seansi rađena su tri donja desna frontalna zuba. Na preoperacionom dijagnostičkom snimku donji desni centralni i lateralni sekutić imali su po jedan vidljiv kanal, dok je očnjak imao dva jasno odvojena kanala (Slika 2). S obzirom na to da smo bili upoznati sa situacijom na levoj strani i da su bila vidljiva dva kanala kod očnjaka na radiogramu, pošlo se od pretpostavke da sva tri zuba imaju po dva kanala. Endodontsko lečenje je izvedeno na isti način kao i kod prethodnog zuba. Ubacivanjem tankih kanalnih instrumenata potvrđena su po dva kanala u sva tri donja frontalna zuba sa desne strane (Slika
5). Kanali su obrađeni i napunjeni takođe lateralnom kompaktažom gutaperke i pastom Acroseal, te su načinjeni radiografski snimci iz dva ugla, na kojima su registrovana po dva kanala (Slike 6 i 7). Na kontrolnom pregledu osam meseci kasnije pacijentkinja nije imala nikakvih subjektivnih tegoba.

\section{DISKUSIJA}

Problem u dijagnostikovanju dva kanala u kliničkim uslovima obično predstavlja superpozicija kanala na radiogramu. Pažljivom analizom radiograma, između ostalog, prati se i pravac pružanja kanala korena, pri čemu se ponekad može uočiti prekid kontinuiteta, što može da ukaže na eventualno udvajanje kanala $[16,17]$. U ovom slučaju istovremeno otežavajuća ali i olakšavajuća okolnost bilo je to što su zubi pre devitalizacije bili ispreparisani za protetičke krunice. Time je mogućnost ekstenzije pristupnog kaviteta bila otežana, jer je trebalo sačuvati kruničnu supstancu, a da se pri tom ne ugrozi ishod endodontskog lečenja. S druge strane, pozicioniranje kanalnog instrumenta pri prvom ispitivanju kanala vidno je ukazivalo na bukalni, a potom i na lingvalni nagib kanalnog instrumenta. Kako su u pitanju bili dvokanalni donji zubi, uključujući i očnjak, trebalo je, radi potvrde kanala i radiografske odontometrije, napraviti nekoliko snimaka iz različitih uglova, što je u jednom slučaju ukazivalo na superpoziciju, a u drugom na postojanje dva razdvojena kanala. Postojanje dva kanala kod mandibularnih sekutića se relativno često javlja [1, 2, 3], što potvrđuju studije in vitro na ekstrahovanim zubima, dok se u kliničkoj praksi često dešava da se jedan od kanala zaboravi, što dovodi do neuspeha endodontske terapije.

Za razliku od mandibularnih inciziva, mnogo se ređe otkrivaju dva kanala u donjem očnjaku. Treba naglasiti da složenost kanalnog sistema kod jednog zuba obično zahteva bolju analizu preostalih zuba i eventualno otkrivanje sličnih. 